\title{
Aflatoxins: Properties, Toxicity and Detoxification
}

\author{
Vankayalapati Vijaya Kumar* \\ Core Green Sugar and Fuels Private Limited, India
}

Submission: April 19, 2018; Published: May 25, 2018

*Corresponding author: Vankayalapati Vijaya Kumar, Core Green Sugar and Fuels Private Limited, Karnataka, India, Tel: +917760874777;

Email: vijayakumarv@coregreen.in

\begin{abstract}
Aflatoxins are the metabolites (mycotoxins) produced mainly by the fungi Aspergillus flavus and A.parasitica. Aflatoxins are first identified in United Kingdom in 1960's, where more than 1,00,000 Turkey poultry birds are killed due the ground nut meal contaminated with A.flavus. Aflatoxins are detected in groundnuts, treenuts, maize, rice, figs and other dried foods, spices and crude vegetable oils and cocoa beans, but the commodities with major risk of aflatoxin contamination are maize, groundnut and cotton seed. Various physical, chemical and biological methods are employed to decontaminate the aflatoxins. This manuscript reviews types of aflatoxins, physical and chemical properties, toxicity, and mode of action and detoxification of aflatoxins in foods.
\end{abstract}

Keywords: Aflatoxin; Aspergillus flavus; A.parasitica; Aflatoxicosis; Mycotoxins; Detoxification

\section{Introduction}

Aflatoxins (a type of Mycotoxins) are a group of approximately 20 related fungal metabolites produced in cereals, maize grains, peanuts and animal feeds mainly by the fungi Aspergillus flavus and Aspergillus parasitica. The other aflatoxin producing species include A.bombycis, A. ochraceoroseus, A. pseudotamari, A.tamarii, Emericella astellata and Emericella venezuelensis, which are scarce in nature and occasionally found in agriculture compared to A.flavus and A.parasitica. Identification of aflatoxin was linked to a groundnut meal contaminated with A.flavus leading to mysterious disease "Turkey $\mathrm{X}$ disease" that killed more than 1,00,000 Turkey poultry birds in England in 1960's. The toxic principles were named as aflatoxins (A.flavus toxins) [1]. Aflatoxin B1 is identified as the most powerful and lethal naturally occurring liver carcinogen. The atmospheric conditions conducive for aflatoxin production are high moisture during harvest, dry weather near crop maturity and inadequate drying and storage of crops [2]. Post harvesting conditions such as transport, storage (excess heat and moisture, pest related damage, long periods of storage) and food processing influence the production of aflatoxins. Aflatoxins are toxic to human and animal health. They cause liver and kidney damage, cause immunosuppressive, carcinogenic and mutagenic effects.

\section{Types of Aflatoxins}

Aflatoxin consists of a group of 20 fungal metabolites. Out of them only B1, B2, G1, G2, M1 and M2 are usually found in foods, where "B" and "G" referring to the blue and green fluorescent colors produced on thin layer chromatography plates under UV light, while the subscript numbers 1 and 2 indicate major and minor compounds, respectively. M1, M2 is the metabolites of B1, B2 found in human and animal milk. Aflatoxin B1 \& B2 are produced by A.flavus and A.parasiticus. Aflatoxin G1 \& G2 are produced by A.parasiticus $[1,3,4]$.

\section{Physical and Chemical Properties of Aflatoxins}

Aflatoxins are colourless to pale yellow crystals, exhibiting fluorescence under UV light. They are slightly soluble in water $(10-20 \mu \mathrm{g} / \mathrm{ml})$ and freely soluble in moderately polar solvents such as chloroform, menthol and dimethyl sulfoxide. They are unstable in UV light in presence of oxygen, unstable in extreme $\mathrm{p} \mathrm{H}(<3$ or $>10)$. The lactone ring opens under alkaline conditions and the aflatoxins are destroyed, but this reaction is reversible on acidification. Ammoniation results in the opening of lactone ring at high temperature, causes decarboxylation of aflatoxins and this reaction is irreversible (Physical and chemical properties of aflatoxins). Some important physical and chemical properties of major aflatoxins are given in Table 1. 
Nutrition \& Food Science International Journal

Table 1: Physical and chemical properties of major aflatoxins.

\begin{tabular}{|c|c|c|c|c|c|c|}
\hline \multirow[t]{2}{*}{ Aflatoxin Name } & \multirow[t]{2}{*}{$\begin{array}{c}\text { Molecular } \\
\text { Formula }\end{array}$} & \multirow[t]{2}{*}{$\begin{array}{l}\text { Molecular } \\
\text { Weight }\end{array}$} & \multirow[t]{2}{*}{ Melting Point } & \multicolumn{2}{|c|}{ Uv absorption (e) } & \multirow[t]{2}{*}{$\begin{array}{l}\text { Fluorescence } \\
\text { Emission (nm) }\end{array}$} \\
\hline & & & & $\Lambda \max (\mathrm{nm})$ & $\begin{array}{c}\varepsilon\left(\mathrm{L} . \mathrm{mol}^{-1} \cdot \mathrm{Cm}^{-1}\right) \\
\times 10^{-3}\end{array}$ & \\
\hline \multirow[t]{3}{*}{ B1 } & C17H12O6 & 312 & $268-269$ & 223 & 25.6 & 425 \\
\hline & & & & 265 & 13.4 & \\
\hline & & & & 362 & 21.8 & \\
\hline \multirow[t]{2}{*}{ B2 } & C17H1406 & 314 & $286-289$ & 265 & 11.7 & 425 \\
\hline & & & & 363 & 23.4 & \\
\hline \multirow[t]{4}{*}{ G1 } & C17H12O7 & 328 & $244-246$ & 243 & 11.5 & 450 \\
\hline & & & & 257 & 9.9 & \\
\hline & & & & 264 & 10 & \\
\hline & & & & 362 & 16.1 & \\
\hline \multirow[t]{2}{*}{ G2 } & C17H1407 & 330 & $237-240$ & 265 & 9.7 & 450 \\
\hline & & & & 363 & 21 & \\
\hline
\end{tabular}

\section{Occurencen and Exposure of Aflatoxins}

Aflatoxins were first identified in 1961 in United Kingdom in animal feed responsible for the deaths of 100000 turkeys. (IARC Monographs, Vol.82). Aflatoxins occur in the crops before harvesting and regarded as the mycotoxins originating from the field compared to the other mycotoxins, which are noticed in the post harvesting of field crops. The exposure of humans and live stock to aflatoxins is through foods such as groundnuts, treenuts, maize, rice, figs and other dried foods, spices and crude vegetable oils and cocoa beans, contaminated with fungi before and after harvest. Consumption of aflatoxin contaminated feed by animals' results in the contamination of milk, eggs and meat. The commodities with major risk of aflatoxin contamination are maize, groundnut and cotton seed. Aflatoxin M1 contaminated milk and milk products, including non-fat dry milk, cheese, ice creams and yogurts, is the result of Aflatoxin-contaminated corn and cottonseed meal in dairy feed. Even in the case of the butter, during its production due to its chemical lipid rich compostion, the accumulation and concentration of any Aflatoxin M1 present in milk usually accumulated in butter during production due to it's high lipid concentration $[5,6]$.

\section{Toxicity and Mode of Action of Aflatoxins}

The aflatoxin B1 is considered as responsible for both toxicity as well as carcinogenicity. It was classified as group I carcinogen by the International Agency for Research on cancer. The diseases caused by the consumption of aflatoxins are known as aflatoxicoses. Chronic aflatoxicosis leads to cancer, immune suppression and other, slow pathological conditions, whereas acute aflatoxicosis leads to death. Liver is the main target organ and liver damage occurred when poultry, fish, rodents and non human primates are fed with the food is contaminated with aflatoxin B1. As the liver is a lipophilic organ, it stores and concentrates all compounds carried by blood stream, i.e. drugs, contaminants, mycotoxins etc., in the hepatocytes and with a long exposure time, may transform themselves into a cancer cell line [5]. Aflatoxins are converted to the reactive 8,9-epoxide form (also known as aflatoxin-2,3 epoxide) which is capable of binding to both DNA and proteins by cytochrome P450 enzymes. . The reactive aflatoxin epoxide binds to the N7 position of guanines. Moreover, aflatoxin B1DNA adducts can result in GC to TA transversions. A reactive glutathione S-transferase system found in the cytosol and microsomes catalyzes the conjugation of activated aflatoxins with reduced glutathione, leading to the excretion of aflatoxins [5]. The LD50 values for aflatoxin B1 and M1 are $\leq 18$ and 12-16 $\mathrm{mg} . / \mathrm{kg}$ bodyweight respectively $[7,8]$.

\section{Detoxification Aflatoxins in Foods}

Different methods employed for decontamination/ detoxification of aflatoxins include physical, chemical or biological methods. The physical, chemical, and microbiological methods must ensure that the degradation process maintains the nutritive value, will not result in the introduction of new toxic or carcinogenic-mutagenic substances, and the process must also destroys Aspergillus spores and mycelia, preventing the proliferation and production of new toxins under favorable conditions. Aflatoxins have low solubility in water. Washing of wheat seeds in water removed $40 \%$ of AFB1.

\section{Physical Methods}

Physical processes involve the separation of the contaminated fractions, removal or inactivation of aflatoxins by physical means, such as heat, cooking, roasting, and 
radiation [9]. Aflatoxins can be separated from the feed by cleaning. Cleaning is a multistep process which removes the dust, husks and products colonized by molds by mechanical sorting and washing. Seperation of discolored seeds/kernels also minimizes the aflatoxin contamination. Aflatoxins have low solubility in water. Hence washing may not remove the aflatoxins from the feeds. However, Hwang \& Lee [9] reported $40 \%$ aflatoxin reduction in contaminated wheat by washing.

Heating is another method of destroying aflatoxins. AFs have high decomposition temperatures ranging from $237^{\circ} \mathrm{C}$ - $306{ }^{\circ} \mathrm{C}$. Various heat treatments such as boiling, roasting, baking and steaming provide a viable mechanism for reducing the AFs concentration in foodstuffs. All processing methods (boiling, roasting, baking and steaming) in maize products (boiled maize, porridge, roti, biscuits, muffins and idli) destroyed AFs to a considerable extent (50-70\%) [10].

Ionizing radiation such a gamma radiation had little effect when used directly in detoxifying the aflatoxins. It indirectly decontaminates the aflatoxins by radiolysis of water, which generates free radicals. Microorganisms inactivation depends on the dosage of gamma radiation, at low dosage (0.1 MRad) was reported to stimulate aflatoxin production in bread and other foods, where as gamma radiation at 0.3-0.4 MRad dosage, suppressed mold growth as well as aflatoxin production [11]. Adsorption is another method of aflatoxin reduction. It involves the binding of toxin compound to the adsorbent compound during digestion in gastro intestinal tract. The compound suitable for absorption are active carbon, diatomaceous earth, alumino (clay, bentonite, montmorillonite, sodium and calcium aluminum silicates mainly zeolite, phyllosilicates and hydrated sodium calcium aluminosilicate (HSCAS)), complex carbohydrates (cellulose and polysaccharides) present at cellular wall of yeasts and bacteria (glucomannans, peptidoglycans), and synthetic polymers (cholestyramine, polyvinyl pyrrolidone, and its derivatives) [12]. Kahdeem et al. [13] studied the effectiveness of yeast, activated charcoal and zeolite either alone or in combination as aflatoxin absorbents in broiler diets. They found that the mixture of absorbents were efficient in reducing the signs of aflatoxin toxicity in growing boilers.

\section{Chemical Methods}

The effective chemical agents that degrade aflatoxins include

a) chlorinating agents such as sodium hypochlorite, chlorine dioxide, and gaseous chlorine

b) Oxidizing agents such as hydrogen peroxide, ozone, and sodium bisulphate and

c) The hydrolytic agents' acids and alkalis. These chemicals either oxidize the double bond of the terminal furan ring or hydrolyze and oxidize the lactone ring of AFB1.
Other chemicals that are tested for aflatoxin degradation are solutions with $75 \%$ methanol, 5\% dimethylamine hydrochloride, aldehydes, benzoyl peroxide, osmium tetroxide, iodine, ferrous ammonium sulphate, potassium permanganate, quinones, sodium borate or formaldehyde. But their use in aflatoxin degradation in foods is limited due to the problems associated with their residues [11].

\section{Biological Methods}

Many bacteria, yeast and fungi are able to degrade aflatoxins in solutions. Flavobacterium (aurantiacum?) NRRL B-184, that could irreversibly removed aflatoxin B1 from aqueous solution has been reported by Ciegler et al. [14]. The bacteria has completely detoxified the toxin contaminated milk, oil, peanut butter, peanuts and corn, where as it partially detoxified the contaminated soyabean. Lillehoj et al. [15] reported that the bacterium F.aurantiacum successfully removed the aflatoxin M1 from naturally contaminated milk. $9.9 \mu \mathrm{g} / \mathrm{ml}$ of aflatoxin was completely removed at a cell concentration of $7.0 \times 1010$ cells $/ \mathrm{ml}$. At $30{ }^{\circ} \mathrm{C}$ after 4 hours of incubation. The other microorganisms capable of converting aflatoxin into aflatoxicol and other compounds include Corynebacterium rubrum, Aspergillus niger, Trichoderma viride, Mucor ambiguus, Dactylium denroides, Mucor griseo cyanus, Absidia repens, Helm inthosporium sativum, Mucor alternans, Rhizopus arrhizus, Rhizopus oryzae, Rhizopus stolonifer, and the protozoan Tetrahymena pyriformis [16].

Molds that are producing aflatoxins are also thought to degrade them by mold mycelia through the action of an enzyme peroxidase. Peroxidase catalyzes the decomposition of hydroperoxides, generating free radicals, which react with aflatoxins. Some peroxidises such as myeloperoxidase, produce hypochlorite and singlet oxygen in the presence of hydrogen peroxide and chloride ion. Aflatoxins are effectively destroyed by hypochlorite [16-18].

\section{Conclusion}

Aflatoxins produced by molds during the preharvesting and postharvest stage of various foods, cause advesre effects on humans and live stock, sometime leading to death. Screening of feedstock for discoloration, presence of molds, proper processing and storage conditions (temperature, moisture, ventilation etc.) are some of the important steps to curtail the spread of aflatoxins. Optimum conditions are to be standardized in prevent the loss of nutrient values in foodstuffs during decontamination. Utmost care should be taken while using chemical agents, as they leave residues leading to further complications. The foodstuffs are to be properly dried before storage and continuous monitoring of storage conditions will help in preventing aflatoxin contamination in humans and live stock. Various physical, chemical and biological methods are employed to detoxify the aflatoxins. It is necessary to properly maintain suitable conditions and records for storage of feed stock, which enables to trace back the aflatoxin contamination 
and to take necessary steps to prevent the aflatoxin contamination.

\section{Acknowledgement}

The author is thankful to the management of Core Green Sugar and Fuels Private Limited for support and encouragement during the preparation of the manuscript.

\section{References}

1. Bennett JW, Kale S, Yu J (2007) Aflatoxins: Background, Toxicology and Molecular Biology. In: Simjee S (ed.), In: Infectious Disease: Foodborne Diseases. Humana Press Inc., Totowa, NJ, USA, pp. 355-373.

2. PACA (2015) Aflatoxin Impacts and Potential Solutions in Agriculture, Trade and Health. An Introduction to Aflatoxin Impacts in Africa IARC Monograph 82. Aflatoxins pp. 172-300.

3. Wacoo AP, Wendiro D, Vuzi PC, Hawumba JF (2014) Methods for Detection of Aflatoxins in Agricultural Food Crops Article ID 706291, pp. 15.

4. Wu F, Narrod C, Tiongco M, Liu Y (2011) The health economics of aflatoxin: global burden of disease. Aflacontrol 4: 1-14.

5. Santini A, Ritieni A (2013) Aflatoxins: Risk, exposure and remediation. In: Aflatoxins: Recent advances and future prospects. RazzaghiAbyaneh M (Ed.) In Tech Open, UK, pp. 343-376

6. Sowley ENK (2016) Aflatoxins: A silent threat in developing countries. Afr J Biotechnol 159(35): 1864-1870.

7. Sharma RK, Parisi S (2017) Toxins and contaminants in Indian food products. Springer International Publishing AG, Switzerland, pp. 1324.

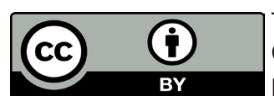

This work is licensed under Creative Commons Attribution 4.0 License DOI: 10.19080/NFSIJ.2018.06.555696
8. Herzallah S, Alshawabkeh K, AL Fataftah AA (2008) Aflatoxin Decontamination of Artificially Contaminated Feeds by Sunlight, Y-Radiation and Microwave Heating. J Appl Poult Res 17(4): 515-521.

9. Hwang JH, Lee KG (2006) Reduction of aflatoxin B1 contamination in wheat by various cooking treatments. Food Chem 98(1): 71-75.

10. Jalili M (2015) A review on aflatoxins reduction in food. Iranian Journal of Health, Safety and Environment 3(1): 445-459.

11. Samarajeewa U, Sen AC, Cohen MD, Wei CI (1990) Detoxification of Aflatoxins in Foods and Feeds by Physical and Chemical Methods. J Food Prot 53(6): 489-501.

12. Huwig A, Freimund S, Kappeli O, Dutler H (2001) Mycotoxin detoxication of animal feed by different adsorbents. Toxicol Lett 122(2): 179-188.

13. Khadem AA, Sharifi SD, Barati M, Borji M (2012) Evaluation of the Effectiveness of Yeast, Zeolite and Active Charcoal as Aflatoxin Absorbents in Broiler Diets. Glob Vet 8(4): 426-432.

14. Ciegler A, Lillehoj EB, Peterson RB, Hall HH (1966) Microbial Detoxification of Aflatoxin. Appl Microbiol 14(6): 934-939.

15. Lillehoj EB, Stubblefield RD, Shannon GM, Shotwell OL (1971) Aflatoxin M1 removal from aqueous solutions by Flavobacterium aurantiacum. Mycopathol Mycol Appl 45(3-4): 259-266.

16. Doyle MP, Applebaum RS, Brackett RE, Marth EH (1982) Physical, chemical and biological degradation of mycotoxins in foods and agricultural commodities. J Food Prot 45(10): 964-971.

17. Wogan GN (1966) Chemical Nature and Biological Effects of the Aflatoxins. Bacteriol Rev 30(2): 360-370.

18. Chemical and physical characteristics of the principal mycotoxins.

\section{Your next submission with Juniper Publishers will reach you the below assets}

- Quality Editorial service

- Swift Peer Review

- Reprints availability

- E-prints Service

- Manuscript Podcast for convenient understanding

- Global attainment for your research

- Manuscript accessibility in different formats

( Pdf, E-pub, Full Text, Audio)

- Unceasing customer service

Track the below URL for one-step submission https://juniperpublishers.com/online-submission.php 